\title{
Vitamin D Deficiency Manifested by Premature Ventricular Complexes from RVOT: A Report on Two Twins
}

\author{
Gabriel Cismaru*, Cecilia Lazea, Daniela Iacob, Simona Cainap \\ "Iuliu Haţieganu" University of Medicine and Pharmacy \\ Cluj-Napoca, Romania
}

\begin{abstract}
Vitamin D receptor is present in almost every cell of the body. Although some studies have suggested that values $>30 \mathrm{ng} / \mathrm{ml}$ would be sufficient, there is no consensus on the optimal values of serum vitamin D. Vitamin D deficiency can lead to "benign" manifestations, such as back pain, joint pain, fatigue, and heavy sweating. Premature ventricular contractions (PVCs) originating from the right ventricular outflow tract (RVOT) are considered "benign," as they occur in patients without structural heart disease and their exact cause remains unknown. We describe the case of a 10-year-old boy with frequent PVCs and vitamin D deficiency that was corrected after vitamin D supplementation. On the contrary, his twin brother had normal serum vitamin D and no PVCs. The disappearance of PVCs occurred after treatment with vitamin D $2000 \mathrm{IU} /$ day.(International Journal of Biomedicine. 2021;11(2):220-223.)
\end{abstract}

Key Words: right ventricular outflow tract $\bullet$ twins $\bullet$ vitamin D $\bullet$ premature ventricular contractions $\bullet 24$-hour Holter ECG

For citation: Cismaru G, Lazea C, Iacob D, Cainap S. Vitamin D Deficiency Manifested by Premature Ventricular Complexes from RVOT: A Report on Two Twins. International Journal of Biomedicine. 2021;11(2):220-223. doi:10.21103/Article11(2)_CR4

\section{Introduction}

A vitamin $\mathrm{D}$ receptor is present in almost every cell in the body, including cardiomyocytes. Although some studies have suggested that values $>30 \mathrm{ng} / \mathrm{ml}$ would be sufficient, there is no consensus on the optimal values of serum vitamin D. Recommendations for normal vitamin D levels are based on research on bone metabolism. According to different studies, the normal value varies between $30 \mathrm{ng} / \mathrm{ml}, 40 \mathrm{ng} / \mathrm{ml}$, and 50 $\mathrm{ng} / \mathrm{ml}$. To date, there is no study that recommends values based on the effects of vitamin D on other systems, such as the heart, or the body's defense against viral infections or cancer.

Vitamin D deficiency can be responsible for manifestations that are considered "benign," such as back pain, joint pain, fatigue, and heavy sweating, or major symptoms such as bone deformities, fractures, slow growth, or seizures. Premature ventricular contractions (PVCs) originating from the right ventricular outflow tract (RVOT) are considered

*Corresponding author: Dr. Gabriel Cismaru, PhD. "Iuliu Hatieganu" University of Medicine and Pharmacy Cluj-Napoca, Romania.E-mail:gabicismaru@yahoo.com "benign," as they occur in patients without structural heart disease and their exact cause remains unknown. In patients with chronic kidney disease and low $25-\mathrm{OH}$ vitamin $\mathrm{D}$, betablockers+vitamin D supplementation was better than betablockers alone in lowering the number of PVCs on 24-hour Holter ECG. ${ }^{(1)}$

Studies on twins provide a solid basis for analysis of environmental influences on a given condition that occurs in one of the children. Our report aims to highlight the changes that occurred in one child with vitamin D deficiency and RVOT PVCs and his twin brother with normal vitamin D and no PVC.

\section{Case Presentation}

We present the clinical case of 2 twins who presented together for a cardiological consultation. Both were 10 years old, one (P.A.) weighing $26 \mathrm{~kg}$ and the second (P.B.) $38 \mathrm{~kg}$. Frequent PVCs were detected in P.A. during a preoperative anesthetic consultation for phimosis. The morphology of the PVCs suggested RVOT origin (Figure 1), with left branch block morphology, low inferior axis, and precordial transition in V4. His twin brother, P.B., had no PVCs on the ECG. 


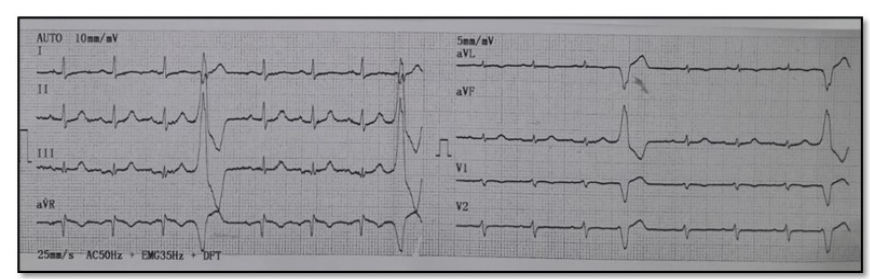

Fig. 1. A 12-lead ECG.

Frequent PVCs with a LBBB morphology and inferior axis.

Cardiac ultrasound was performed on both, and was normal, with right and left cavities of normal size, normal systolic function, ejection fraction of $60 \%$, and no valvulopathies were noted. The next examination was a 24hour Holter ECG, which showed high burden of PVCs in P.A.: 47.640, evenly distributed during the 24 hours, both during the day and night (Figure 2). During physical exertion, PVCs disappeared. All these characteristics were suggestive of "benign" PVC and were associated with a serum vitamin D value of $24.7 \mathrm{ng} / \mathrm{ml}$. Propranolol 2x10mg had no effect in lowering the PVC burden. On the other hand, P.B. had no PVCs in the 24-hour Holter ECG, and serum 15-OH vitamin $\mathrm{D}$ had a value of $30.5 \mathrm{ng} / \mathrm{ml}$.

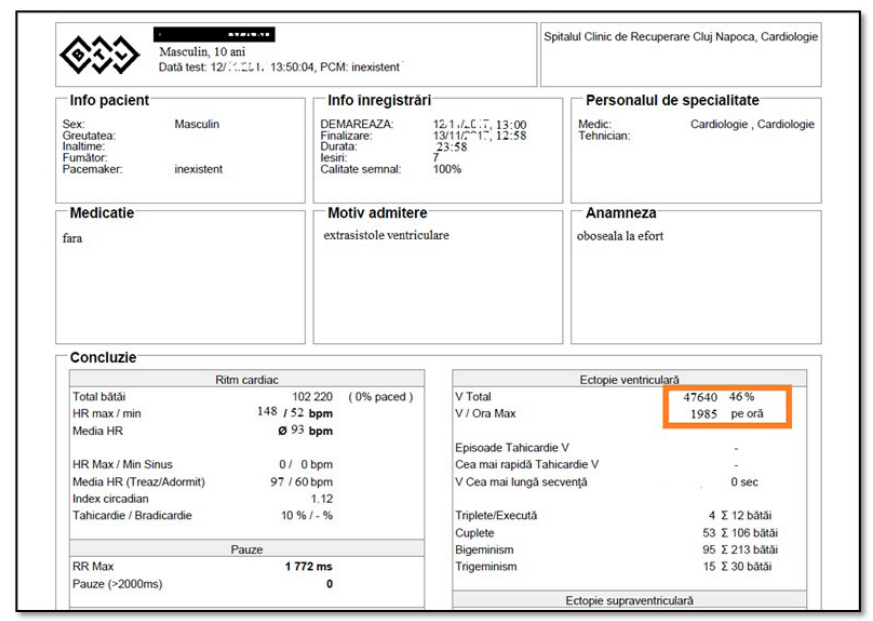

Fig. 2. A 24-hour Holter ECG.

A high burden of PVCs (47.640).

Given the low value of serum vitamin D in P.A. and the fact that PVCs were "benign," it was decided not to administer antiarrhythmic medication but to supplement the intake of vitamin D. Thus, we began with 2000 UI daily, and after 4 months the value of $25 \mathrm{OH}$-vitamin D increased to $35.5 \mathrm{ng} / \mathrm{ml}$ and the number PVCs decreased to 11.728 per 24 hours. The same dose of $2000 \mathrm{IU} / 24$ hours was continued and after 3 months it reached a value of $41 \mathrm{ng} / \mathrm{ml}$ and 3800 PVCs per 24 hours. After another 3 months $25-\mathrm{OH}$ vitamin D was $47.3 \mathrm{ng} / \mathrm{ml}$ and 1400 PVCs per 24 hours were present in the Holter ECG (Figure 3). On the contrary, P.B. had serum 25-OH vitamin D values of $30.5 \mathrm{ng} / \mathrm{ml}$ and no PVC was present in 24-hour Holter ECG.

The father of the twins gave informed consent for the publication of the case report, except images with their face that could reveal their identity. Publication of the report was approved by the Ethics Committee of the Rehabilitation Hospital.

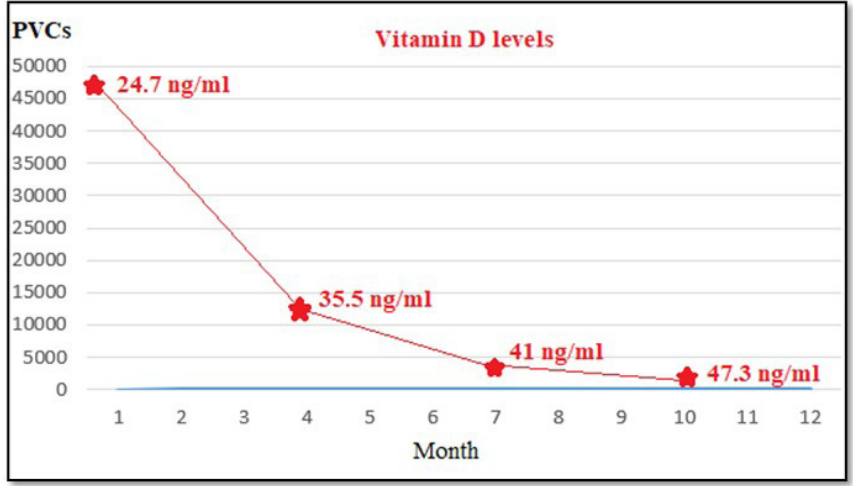

Fig. 3. Association between serum 25-OH vitamin $D$ level and PVC number on 24-hour Holter ECG.

\section{Discussion}

We presented the case of two twins: one with vitamin D deficiency and frequent PVCs and the other with normal serum vitamin D level and absence of PVCs. The supplementation of vitamin D 2000 IU/day in the first child led to normalization of the serum value in about 10 months with a significant decrease in the number of PVCs, so that no antiarrhythmic drug treatment or catheter ablation was needed.

Our patient did not use other medicines during treatment with vitamin D, and the number of PVCs decreased significantly. Even if there are seasonal variations ${ }^{(2)}$ in serum levels of 25-OH vitamin $\mathrm{D}$, they can not explain the dramatic decrease in the number of PVCs from 47,360 to 1400 per 24 hours.

As this was the first dosage of vitamin D in the twins, it is not possible to specify whether the deficiency was present at birth or was acquired along the way. It is known that children born from twin pregnancies suffer more often from vitamin $\mathrm{D}$ deficiency because the need is higher than in single children. ${ }^{(3,4)}$ To supplement vitamin D deficiency, different therapeutic regimens and doses have been tried: $1000 \mathrm{IU} /$ day for 12 months, ${ }^{(5)} 2000 \mathrm{IU} /$ day for 3-6 months, ${ }^{(6,7)} 2500 \mathrm{IU} /$ day for 4-6 months, ${ }^{(8,9)} 5000 \mathrm{IU} /$ day for 3 months. ${ }^{(10)} \mathrm{We}$ used $2000 \mathrm{IU} /$ day in a $26 \mathrm{~kg}$ child and it took about 10 months to reach a value close to $50 \mathrm{ng} / \mathrm{ml}$.

When the PVC burden is high, catheter ablation is generally indicated for $>24 \%$ per 24 hours. ${ }^{(11)}$ This can be done by inserting a catheter in the right ventricle and searching for the focus responsible for PVCs. Usually, for this morphology of PVCs, the focus is located in the RVOT, and it can be destroyed with 30-50W energy applications of radiofrequency current. ${ }^{(12)}$ But ablation is an invasive technique and most patients prefer the less invasive alternative (ie antiarrhythmics) or no drug. It is known that PVCs are induced by excess calcium through an increased level of cAMP in cardiomyocytes, which in turn leads to increased intracellular calcium inflow. ${ }^{(13)}$ There are several causes of this phenomenon, and vitamin D deficiency can lead to increased cAMP concentration and thus increased intracellular calcium inflow. Therefore, it is important to detect a deficiency of serum vitamin D because it would be possible to act directly on the cause that determined the occurrence of PVCs. 
Cardiomyocyte beta1-adrenergic receptor can activate guanosine nucleotide-binding protein, and lead to increased cAMP, hence the beneficial effect of beta-blockers in the treatment of PVCs. Unfortunately, our patient's treatment with propranolol failed to reduce the number of PVCs; therefore, vitamin D supplementation seemed the most reasonable action. One explanation for the failure of beta-blockers to control PVCs might be given by Weishaar et al., ${ }^{(14)}$ who found no difference in serum catecholamine levels between 1) vitamin D sufficient; 2)vitamin D deficient with hypocalcemia and c)vitamin D deficient with normocalcemia rats.

Furthermore, vitamin D deficiency is associated with increased parathormone PTH levels, which decreases cellular calcium intake and reduces calcium reuptake to the sarcoplasmic reticulum, and therefore increases intracellular calcium levels; this might be the mechanism related to the development of PVCs from RVOT. ${ }^{(15)}$ Therefore, we believe that beta-blockers have a mild effect on PVC burden in patients with a high number PVCs and vitamin D deficiency, which was also confirmed by the study of Kiuchi et al.(1) Furthermore, in a recent report ${ }^{(16)}$ vitamin D supplementation associated with cardiac rehabilitation decreased the PVC burden in Holter ECG more than cardiac rehabilitation alone.

Although some studies have suggested that values $>30$ $\mathrm{ng} / \mathrm{ml}$ would be sufficient, there is no consensus on the optimal values of serum vitamin D. The Endocrine Society has set the lower threshold for normal vitamin D plasmatic concentration to $30 \mathrm{ng} / \mathrm{ml}$ or $75 \mathrm{nmol} / \mathrm{l}$. These levels were demonstrated to maintain bone health but there is no data for optimal levels that protect against viral infections, cancers, atherosclerosis, or other health problems. ${ }^{(17)}$ Garland et al. ${ }^{(18)}$ suggested that increasing 25(OH)D to a range of 40 to $60 \mathrm{ng} / \mathrm{ml}$ from the current US average could reduce the risk of breast cancer by $25 \%$ and colon cancer by $27 \%$.

We believe that for cardiac health, especially in patients with PVCs, the optimal level of serum 25-OH vitamin D should be $>50 \mathrm{ng} / \mathrm{ml}$. Studies should be conducted to determine the optimal level of vitamin D in this category of patients.

It is important to note that P.A. had frequent PVCs in the context of a level of vitamin D-25 of $24.7 \mathrm{ng} / \mathrm{ml}$. So what should be the optimal level of serum vitamin $\mathrm{D}$ ? Is the value of $30 \mathrm{ng} / \mathrm{ml}$ as it appears in bone health studies sufficient? It seems that this value would be insufficient because the PVCs of P.A. decreased significantly at a level of $47.3 \mathrm{ng} / \mathrm{ml}$. However, even this value of vitamin D did not lead to the total disappearance of PVCs, which remained at 1400 per 24 hours. It is not known what value of $25-\mathrm{OH}$ vitamin $\mathrm{D}$ is needed to obtain the total resolution of PVCs. Or should another calcium or magnesium supplement be added to help the resolution of PVCs? Further studies should resolve these questions.

\section{Conclusion}

We presented the case of two twins: one with vitamin D deficiency and frequent PVCs and the other with normal serum vitamin D level and absence of PVCs. The supplementation of vitamin D $2000 \mathrm{IU} /$ day in the first child led to normalization of the serum value in about 10 months with a significant decrease in the number of PVCs, so that no antiarrhythmic drug treatment or catheter ablation was needed.

\section{Competing Interests} interests.

\section{References}

1. Kiuchi MG, e Silva GR, Paz LMR, Chen Sh, Hoye NA, Souto GLL. Influence of vitamin D levels on the treatment of premature ventricular complexes in patients with chronic kidney disease. IJC Metabolic \& Endocrine. 2017;14:53-58.

2. Snellman G, Melhus H, Gedeborg R, Olofsson S, Wolk A, Pedersen NL, Michaëlsson K. Seasonal genetic influence on serum 25-hydroxyvitamin D levels: a twin study. PLoS One. 2009 Nov 13;4(11):e7747. doi: 10.1371/journal. pone.0007747. Erratum in: PLoS One. 2010;5(9) doi: 10.1371/ annotation/e85fe043-b072-422d-acd5-9d27f02390b3.

3. Frasca D, Morganti G, Cherubini S. Un caso di rachitismo carenziale in una coppia di gemelli [Nutritional rickets in twins: a case report]. Pediatr Med Chir. 2013 May-Jun;35(3):130-3. doi: 10.4081/pmc.2013.46. [Article in Italian].

4. Goswami D, Rani R, Saxena A, Arora MS, Batra S, Sreenivas V. Maternal and neonatal vitamin-D status in twin versus singleton pregnancies. J Obstet Gynaecol Res. 2016 Oct;42(10):1250-1257. doi: 10.1111/jog.13060.

5. Breslavsky A, Frand J, Matas Z, Boaz M, Barnea Z, Shargorodsky M. Effect of high doses of vitamin D on arterial properties, adiponectin, leptin and glucose homeostasis in type 2 diabetic patients. Clin Nutr. 2013 Dec;32(6):970-5. doi: 10.1016/j.clnu.2013.01.020.

6. Moghassemi S, Marjani A. The effect of short-term vitamin D supplementation on lipid profile and blood pressure in post-menopausal women: A randomized controlled trial. Iran J Nurs Midwifery Res. 2014 Sep;19(5):517-21.

7. Ryu OH, Chung W, Lee S, Hong KS, Choi MG, Yoo HJ. The effect of high-dose vitamin D supplementation on insulin resistance and arterial stiffness in patients with type 2 diabetes. Korean J Intern Med. 2014 Sep;29(5):620-9. doi: 10.3904/kjim.2014.29.5.620.

8. Gepner AD, Ramamurthy R, Krueger DC, Korcarz CE, Binkley N, Stein JH. A prospective randomized controlled trial of the effects of vitamin D supplementation on cardiovascular disease risk. PLoS One. 2012;7(5):e36617. doi: 10.1371/ journal.pone.0036617.

9. Gepner AD, Haller IV, Krueger DC, Korcarz CE, Binkley N, Stein JH. A randomized controlled trial of the effects of vitamin D supplementation on arterial stiffness and aortic blood pressure in Native American women. Atherosclerosis. 2015 Jun;240(2):526-8. doi: 10.1016/j. atherosclerosis.2015.04.795.

10. Yiu YF, Yiu KH, Siu CW, Chan YH, Li SW, Wong LY, Lee SW, Tam S, Wong EW, Lau CP, Cheung BM, Tse HF. Randomized controlled trial of vitamin D supplement on endothelial function in patients with type 2 diabetes. Atherosclerosis. 2013 Mar;227(1):140-6. doi: 10.1016/j. atherosclerosis.2012.12.013.

11. Muresan L, Cismaru G, Martins RP, Bataglia A, Rosu R, Puiu M, Gusetu G, Mada RO, Muresan C, Ispas DR, Le Bouar R, Diene LL, Rugina E, Levy J, Klein C, Sellal JM, Poull IM, 
Laurent G, de Chillou C. Recommendations for the use of electrophysiological study: Update 2018. Hellenic J Cardiol. 2019 Mar-Apr;60(2):82-100. doi: 10.1016/j.hjc.2018.09.002. 12. Cismaru G, Mester P, Muresan L, Rosu R, Gusetu G, Puiu M, Pop D, Mircea PA, Zdrenghea D. Idiopathic ventricular premature contractions originating from the postero-lateral tricuspid annulus leading to left ventricular disfunction. Int $\mathrm{J}$ Clin Exp Med. 2015 Mar 15;8(3):4690-3.

13. Nelson DL, Lehninger AL, Cox MM. Lehninger Principles of Biochemistry (5th ed.). New York: W.H. Freeman; 2008

14. Weishaar RE, Kim SN, Saunders DE, Simpson RU. Involvement of vitamin D3 with cardiovascular function. III. Effects on physical and morphological properties. Am J Physiol. 1990 Jan;258(1 Pt 1):E134-42. doi: 10.1152/ ajpendo.1990.258.1.E134.

15. Rostand SG, Drüeke TB. Parathyroid hormone, vitamin $\mathrm{D}$, and cardiovascular disease in chronic renal failure.
Kidney Int. 1999 Aug;56(2):383-92. doi: 10.1046/j.15231755.1999.00575.x.

16. Cismaru G, Gurzau D, Fringu F, Martis A. Vitmamin D supplementation with Cardiac Rehabilitation reduces the number of RVOT Premature Ventricular Contractions. Balneo Research Journal. 2020;11(4):566-568

17. Holick MF, Binkley NC, Bischoff-Ferrari HA, Gordon CM, Hanley DA, Heaney RP, Murad MH, Weaver CM; Endocrine Society. Evaluation, treatment, and prevention of vitamin D deficiency: an Endocrine Society clinical practice guideline. J Clin Endocrinol Metab. 2011 Jul;96(7):1911-30. doi: 10.1210/jc.2011-0385. Epub 2011 Jun 6. Erratum in: J Clin Endocrinol Metab. 2011 Dec;96(12):3908.

18. Garland CF, Gorham ED, Mohr SB, Garland FC. Vitamin D for cancer prevention: global perspective. Ann Epidemiol. 2009 Jul;19(7):468-83. doi: 10.1016/j. annepidem.2009.03.021. 